\title{
STABILITY INDICATIVE AND COST EFFECTIVE ANALYTICAL METHOD DEVELOPMENT AND VALIDATION OF FAVIPIRAVIR AND PERAMIVIR IN BULK AND PHARMACEUTICAL DOSAGE FORM BY USING RP-HPLC
}

\author{
SRINIVAS LINGABATHULA*, NEELU JAIN \\ Sri Satya Sai University of Technology and Medical Sciences, Sehore, (M. P.), India \\ ${ }^{*}$ Email: Isrinivas19888@gmail.com \\ Received: 17 Dec 2020, Revised and Accepted: 29 May 2021
}

\begin{abstract}
Objective: The current investigation was pointed at developing and progressively validating novel, simple, responsive and stable RP-HPLC method for the measurement of active pharmaceutical ingredients of Favipiravir and Peramivir and their related substances.

Methods: A simple, selective, validated and well-defined stability that shows gradient RP-HPLC methodology for the quantitative determination of Favipiravir and Peramivir. The chromatographic strategy utilized Inertsil ODS column of dimensions 250x4.6 mm, 5 micron, using isocratic elution with a mobile phase of acetonitrile and 0.1 percent orthophosphoric acid (70:30). A flow rate of $1 \mathrm{ml} / \mathrm{min}$ and a detector wavelength of $260 \mathrm{~nm}$ utilizing the PDA detector was given in the instrumental settings. Using the impurity-spiked solution, the chromatographic approach was streamlined.

Results: Validation of the proposed method was carried out according to an international conference on harmonization (ICH) guidelines. LOD and LOQ for the two active ingredients and their impurities were established with respect to test concentration. The calibration charts plotted were linear with a regression coefficient of $\mathrm{R}^{2}>0.999$, which means the linearity was within the limit. Recovery, specificity, linearity, accuracy, robustness,
\end{abstract} ruggedness was determined as a part of method validation and the results were found to be within the acceptable range.

Conclusion: The proposed method to be fast, simple, feasible and affordable in RS condition. During stability tests, it can be used for routine analysis of production samples and to verify the quality of drug samples during stability studies.

Keywords: Favipiravir, Peramivir, RP-HPLC, Development, Validation

(c) 2021 The Authors. Published by Innovare Academic Sciences Pvt Ltd. This is an open access article under the CC BY license (https://creativecommons.org/licenses/by/4.0/) DOI: https://dx.doi.org/10.22159/ijap.2021v13i4.40530. Journal homepage: https://innovareacademics.in/journals/index.php/ijap

\section{INTRODUCTION}

Peramivir (trade name Rapivab) is an antiviral medication developed for the treatment of influenza by BioCryst pharmaceuticals [1]. In October 2009, the experimental antiviral drug peramivir was confirmed to be "life saving" effective in the intravenous treatment of 8 extreme cases of swine flu [2]. On October 23, the U. S. An emergency use authorization for peramivir was provided bt the Food and Drug Administration (FDA), authorizing the use of the drug in intravenous form for hospitalized parents only in cases where the other treatment options available are inadequate or unavailable [3]. Two new antiinfluenza medications were launched clinically in Japan in 2010. Rapiacta (peramivir), which is provided by intravenous drip injection, was one of them [4-6]. Peramivir was the first intravenous neuraminidase inhibitor (NAI) approved by the US food and drug administration (FDA) for the treatment of influenza [7]. Data from randomized controlled trails have shown that peramivir is safe and well-tolerated in uncomplicated influenza, with similar or superior clinical efficacy to those of placebo and oseltamivir [8-10]. Signs of an allergic reaction hive, difficult breathing, swelling in face or throat, severe skin reactions [11]. Favipiravir, sold under the brand name Avigan among others, is an antiviral medication used to treat influenza in Japan [12]. It is also being studied to treat a number of other viral infections [13]. There is evidence that use of during pregnancy may result in harm to the baby $[14,15]$. Research in 2014, suggested that Favipiravir may have efficacy in humans, it went unaddressed.

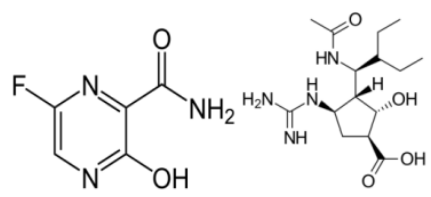

A$$
\text { B }
$$

Fig. 1: Structure of (A) Favipiravir and (B) Peramivir

\section{MATERIALS AND METHODS}

\section{Chemicals}

Acetonitrile, HPLC-grade orthophosphoric acid, water, were purchased from Merck India Ltd, Mumbai, India. APIs of Favipiravir, Peramivir standards were procured from Glen mark, Mumbai.

\section{The instrumentation}

Waters alliance liquid chromatography (model 2695) monitored with empower 2.0 data handling system and a detector of photodiode array (model 2998) was used for this study [16].

\section{Method optimization}

To optimize the chromatographic conditions, different ratios of phosphate buffer and the acetonitrile in the mobile phase with isocratic and gradient mode were tested. However, the mobile phase composition was modified at each trial to enhance the resolution and also to achieve acceptable retention times. Finally, 0.1\% OPA buffer and acetonitrile with isocractic elution was selected because it results in a greater response of active pharmacy ingredient and their impurities. During the optimization of the method various stationary phases such as $\mathrm{C}_{8}, \mathrm{C}_{18}$ phenyl and amino, inertsil ODS columns were tested. From these trials the peak shapes were relatively good with a inertsil ODS column of $250 \times 4.6 \mathrm{~mm}, 5 \mu$ with a PDA detector. The mobile phase flow rate has been done at $254 \mathrm{~nm}$ in order to obtain enough sensitivity. By using above conditions we get retention times of Favipiravir and Peramivir were about 3.003 and 7.271 min with a tailing factor of 1.063 and 1.401 . The number of theoretical plates for Favipiravir and Peramivir were 2089456,1889412 which indicate the column's successful output the $\%$ RSD for six replicate injections was around $0.94 \%$ the proposed approach suggests that it is extremely precise. According to ICH guidelines, the method established was validated.

There are some HPLC methods [17-19] reported in the literature, but these methods are developed only for routine analysis of ESC 
and FLU in bulk and formulation studies. The developed HPLC method was utilized for the estimation of the combined drugs by in vitro method. Different extractions were tried using acetonitrile, methanol, and dimethylformamide [20].

\section{Validation procedure}

The analytical parameters such as system suitability, precision, specificity, accuracy, linearity, robustness, LOD, LOQ forced degradation and stability were validated according to ICH Q2 (R1) guidelines [21-29].

\section{Preparation of buffer}

$1 \mathrm{ml}$ of ortho phosphoric acid is dissolved in $1 \mathrm{lt}$ of HPLC grade water and filter through $0.45 \mu$ filter paper.

\section{Chromatographic conditions}

The HPLC analysis was performed on reverse phase HPLC system with isocratic elution mode using a mobile phase of acetonitrile and $0.1 \%$ OPA and Inertsil ODS column $(250 \times 4.6 \mathrm{~mm}, 5 \mu)$ column with a flow rate of $1 \mathrm{ml} / \mathrm{min}$.

\section{Diluent}

Water and Acetonitrile in the ratio (50:50) is used as diluent.

\section{Preparation of the standard stock solution}

For standard stock solution preparation, add $70 \mathrm{ml}$ of diluents to $100 \mathrm{mg}$ of Favipiravir and $100 \mathrm{mg}$ of Peramivir taken in a $100 \mathrm{ml}$ volumetric flask and sonicate for $10 \mathrm{~min}$ to fully dissolve the contents and then make up to the mark with diluent.

\section{Preparation of standard solution}

$1 \mathrm{ml}$ of solution is drawn from the above normal stock solution into a $10 \mathrm{ml}$ volumetric flask and diluted up to the level.

\section{Preparation of sample solution}

Take $130 \mathrm{mg}$ of the sample drug Favipiravir and $100 \mathrm{mg}$ of the sample drug Peramivir into a $100 \mathrm{ml}$ volumetric flask and add $70 \mathrm{ml}$ of diluents and sonicate for $10 \mathrm{~min}$ to fully dissolve the contents and then make up the mark with diluent. This solution is filtered into a device using a $0.45 \mu$ nylon syringe in a vial.

\section{RESULTS AND DISCUSSION}

The main analytical challenge during the development of a new method was to separate active Pharma ingredients from their impurities. In order to provide a good performance, the chromatographic conditions were optimized.

\section{System suitability}

In System, suitability injecting standard solution and reported USP tailing and plate count values are tabulated in table 1.

\section{Specificity}

In this test method placebo, sample and standard solutions were analyzed individually to examine the interference. The below fig. shows that the active ingredients were well separated from blank and their excipients and there was no interference of placebo with the principal peak. Hence the method is specific.

Table 1: Results of system suitability

\begin{tabular}{lllc}
\hline System suitability parameter & Acceptance criteria & Drug name & Peramivir \\
\cline { 2 - 4 } & & Favipiravir & 3264 \\
USP Plate Count & NLT 2000 & 38417 & 1.04 \\
USP Tailing & NMT 2.0 & 1.07 & 8.64 \\
USP Resolution & NLT 2.0 & - & 0.89 \\
\% RSD & NMT 2.0 & 0.71 & \\
\hline
\end{tabular}

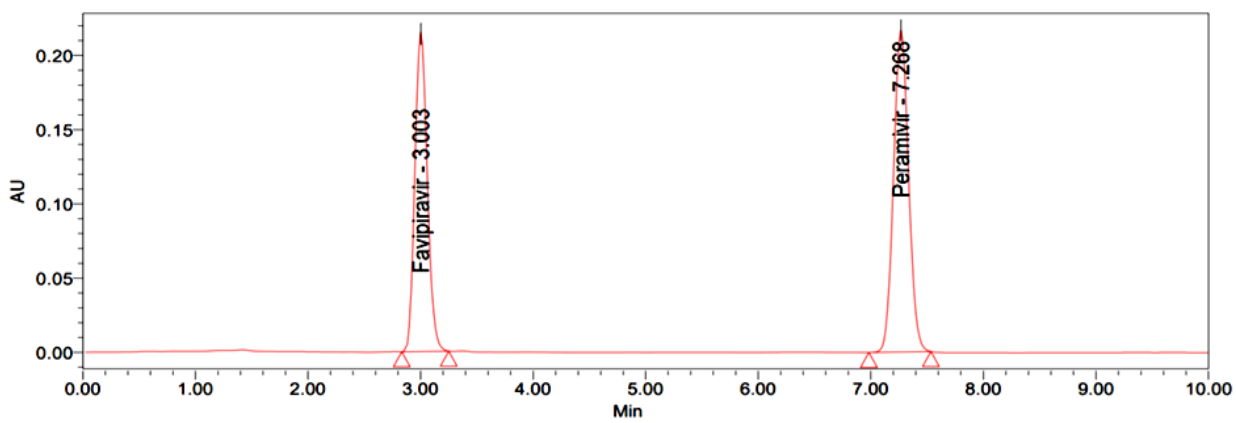

Fig. 2: Chromatogram of system suitability

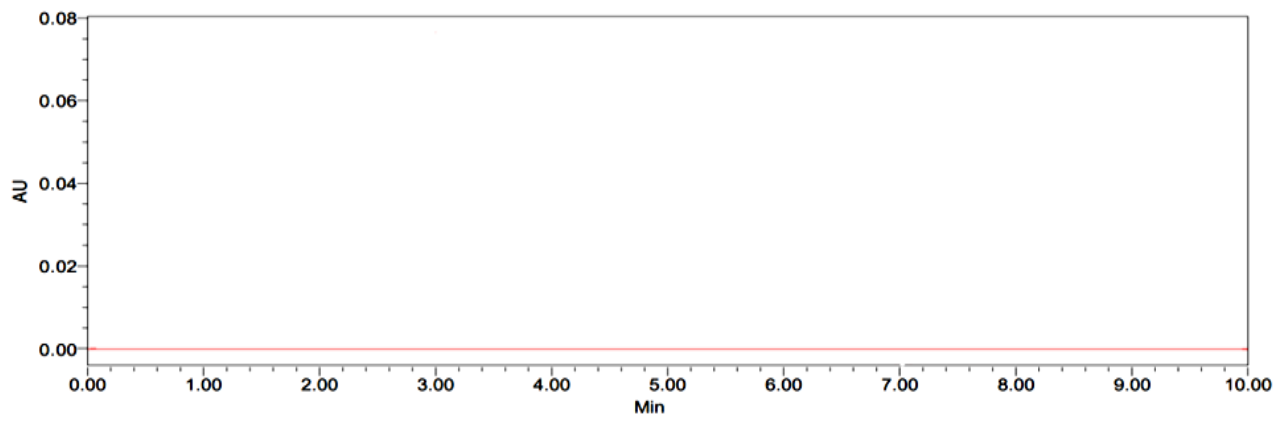

Fig. 3: Chromatogram of blank 
Table 2: Linearity of favipiravir and peramivir

\begin{tabular}{|c|c|c|c|c|}
\hline S. No. & Conc $\mu \mathrm{g} / \mathrm{ml}$ & Favipiravir area count & Conc. $\mu \mathrm{g} / \mathrm{ml}$ & Peramivir area count \\
\hline 1 & 10 & 208946 & 10 & 188941 \\
\hline 2 & 25 & 509623 & 25 & 460832 \\
\hline 3 & 50 & 1044728 & 50 & 944706 \\
\hline 4 & 75 & 1554351 & 75 & 1405538 \\
\hline 5 & 100 & 2089456 & 100 & 1889419 \\
\hline 6 & 125 & 2599079 & 125 & 2350244 \\
\hline 7 & 150 & 3134184 & 150 & 2834118 \\
\hline Correl coef & & 0.99998 & & 0.9999 \\
\hline Slope & & 20879.909 & & 18880.871 \\
\hline intercept & & 3797.945 & & 3434.331 \\
\hline
\end{tabular}

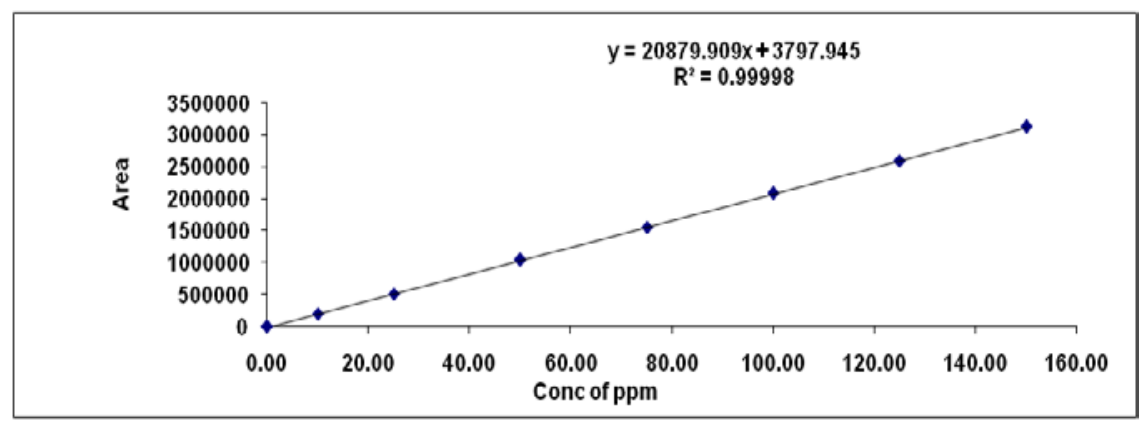

A

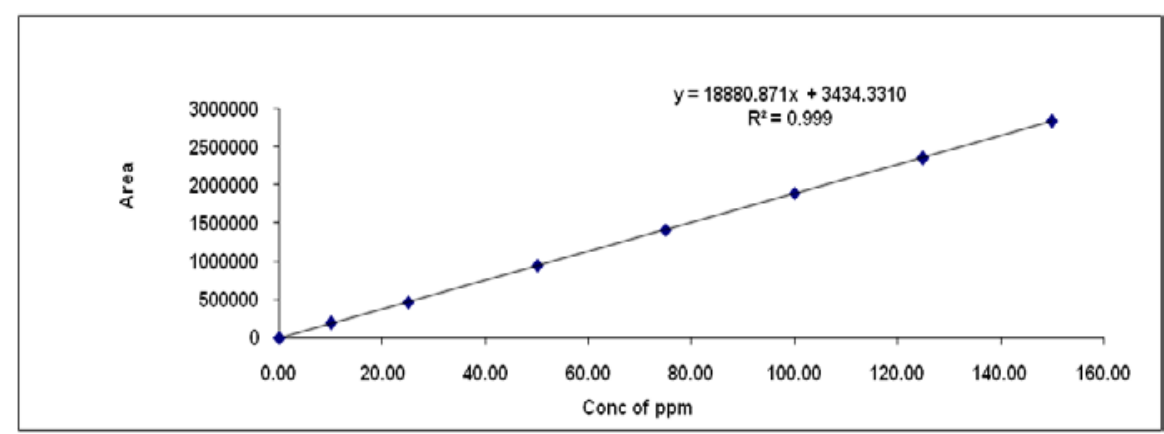

Fig. 4: Calibration plots of (A) Favipiravir (B) Peramivir

\section{Linearity}

The area of the linearity peak versus different concentrations has been evaluated for Favipiravir, Peramivir, as 10,25,50,75,100,125,150 percent respectively. Linearity was performed in the range of 10$150 \mu \mathrm{g} / \mathrm{ml}$ of Favipiravir and $10-150 \mu \mathrm{g} / \mathrm{ml}$ of Peramivir. The correlation coefficients achieved greater than 0.999 for all.

\section{Accuracy}

In this method, Accuracy was conducted in triplicate by analyzing active pharma ingredient sample solution spiked with known amounts of all the impurities at three kinds of concentration levels of 50, 100 and $150 \%$ of each at a specified limit. For all impurities, percentage recoveries were measured and found to be within the limit. The accuracy and reliability of the developed method were established. The percentage recovery values were found to be in the range of $100.154-100.624 \%$ for Favipiravir and $99.512-99.918 \%$ for Peramivir. The results are given in table 3,4 and 5.

\section{Precision}

In method precision study prepare six different samples in the concentration of Favipiravir (100 ppm) and Peramivir (100 ppm) are injected into HPLC system. Favipiravir \%assay found to be in the range of 100.136-100.561 and Peramivir \%assay found to be in range of 100.261-100.517. These results are given below table 4 .

Table 3: Results of accuracy

\begin{tabular}{llll}
\hline S. No. & \% Level & Favipiravir \% recovery & Peramivir \% recovery \\
\hline 1 & 50 & 100.154 & 99.512 \\
2 & 100 & 100.624 & 99.861 \\
3 & 150 & 100.417 & 99.981 \\
mean & & 100.534 & 99.78467 \\
SD & & 0.106108 & 0.24364 \\
\hline
\end{tabular}

Mean+SD $(n=3)$ 
Table 4: Intraday precision results of favipiravir and peramivir

\begin{tabular}{|c|c|c|c|c|c|c|}
\hline \multicolumn{3}{|c|}{ Favipiravir } & & \multicolumn{3}{|l|}{ Peramivir } \\
\hline S. No. & Conc. $(\mu \mathrm{g} / \mathrm{ml})$ & Area counts & $\%$ assay as is & Conc. $(\mu \mathrm{g} / \mathrm{ml})$ & Area counts & $\%$ assay as is \\
\hline 1 & & 2089456 & 100.561 & & 1889419 & 100.264 \\
\hline 2 & 100 & 2089451 & 100.478 & 100 & 1889426 & 100.517 \\
\hline 3 & & 2089444 & 100.362 & & 1889435 & 100.284 \\
\hline 4 & & 2089441 & 100.287 & & 1889441 & 100.361 \\
\hline 5 & & 2089420 & 100.514 & & 1889422 & 100.485 \\
\hline 6 & & 2089450 & 100.136 & & 1889434 & 100.234 \\
\hline \% RSD & 1.06 & & & 0.918 & & \\
\hline mean & 100.3897 & & & 100.3575 & & \\
\hline SD & 0.160168 & & & 0.119252 & & \\
\hline
\end{tabular}

Mean+SD $(n=6)$

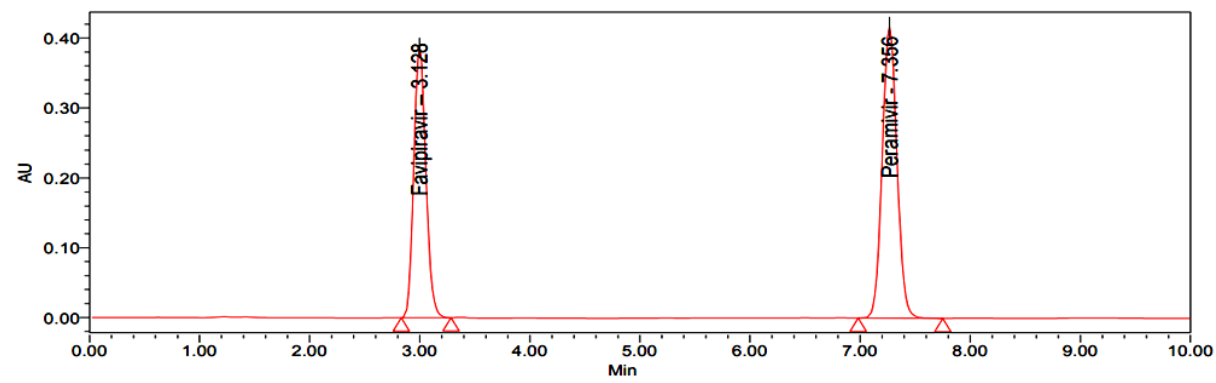

Fig. 5: Chromatogram of sample

\section{Intermediate precision}

Six replicates of the sample solution were studied by various researchers, and on separate days different instruments were tested. The peak regions used to determine mean percent RSD values have been calculated. The results are given in the following table.

\section{Intraday precision}

Six replicates of a sample solution containing Favipiravir $(100 \mu \mathrm{g} / \mathrm{ml})$ and Peramivir $(100 \mu \mathrm{g} / \mathrm{ml})$ were analysed on the same day. Peak areas were calculated, which were used to calculate mean, SD and \%RSD values.

\section{Interday precision}

Six replicates of a sample solution containing Favipiravir $(100 \mu \mathrm{g} / \mathrm{ml})$ and Peramivir $(100 \mu \mathrm{g} / \mathrm{ml})$ were analysed on a different day. Peak areas were calculated which were used to calculate mean, SD and \%RSD values. The present method was found to be precise as the RSD values were less than $2 \%$ and also the percentage assay values were close to be $100 \%$. The results are given in table 5 [16].

Table 5: Inter-day outcomes of accuracy of favipiravir and peramivir

\begin{tabular}{|c|c|c|c|c|c|c|}
\hline \multicolumn{4}{|c|}{ Favipiravir } & \multicolumn{3}{|l|}{ Peramivir } \\
\hline S. No. & Conc. $(\mu \mathrm{g} / \mathrm{ml})$ & Area counts & \% assay as is & Conc. $(\mu \mathrm{g} / \mathrm{ml})$ & Area count & \% assay as is \\
\hline 1 & & 2089451 & 100.241 & & 1889414 & 100.482 \\
\hline 2 & 100 & 2089461 & 100.054 & 100 & 1889406 & 100.612 \\
\hline 3 & & 2089312 & 100.354 & & 1889396 & 100.536 \\
\hline 4 & & 2089366 & 100.687 & & 1889354 & 100.417 \\
\hline 5 & & 2089414 & 100.471 & & 1889341 & 100.532 \\
\hline 6 & & 2089457 & 100.289 & & 1889411 & 100.417 \\
\hline$\%$ RSD & 0.89 & & & 1.04 & & \\
\hline Mean & 2089410 & & & 100.4993 & & \\
\hline SD & 60.078 & & & 0.07611 & & \\
\hline
\end{tabular}

Mean+SD $(n=6)$

\section{LOD and LOQ}

The LOD concentrations for Favipiravir are $1.818 \mu \mathrm{g} / \mathrm{ml}$ and $\mathrm{s} / \mathrm{n}$ values is 8 and Peramivir $1.818 \mu \mathrm{g} / \mathrm{ml}$ and $\mathrm{s} / \mathrm{n}$ value 6 . The LOQ concentration for Favipiravir $6.248 \mu \mathrm{g} / \mathrm{ml}$ and their $\mathrm{s} / \mathrm{n}$ values are 23 and Peramivir their $6.248 \mu \mathrm{g} / \mathrm{ml}$ and $\mathrm{s} / \mathrm{n}$ value is 28 . The method is validated as per the US FDA guidelines [30].

\section{Robustness}

The conditions of the experiment were designed to test the robustness of the established system intentionally altered, such as flow rate, mobile phase in organic percentage in all these varied conditions. Robustness results for favipiravir and peramivir found to be within the limit and results are tabulated in table 7.

Table 6: LOD and LOQ for favipiravir and peramivir

\begin{tabular}{|c|c|c|c|c|c|c|c|}
\hline \multicolumn{4}{|l|}{ Favipiravir } & \multicolumn{4}{|l|}{ Peramivir } \\
\hline LOD & & LOQ & & LOD & & LOQ & \\
\hline Concentration & $\mathrm{s} / \mathrm{n}$ & Concentration & $\mathrm{s} / \mathrm{n}$ & concentration & $\mathrm{s} / \mathrm{n}$ & Concentration & $\mathrm{s} / \mathrm{n}$ \\
\hline $1.818 \mu \mathrm{g} / \mathrm{ml}$ & 8 & $6.248 \mu \mathrm{g} / \mathrm{ml}$ & 23 & $1.818 \mu \mathrm{g} / \mathrm{ml}$ & 6 & $6.248 \mu \mathrm{g} / \mathrm{ml}$ & 28 \\
\hline
\end{tabular}




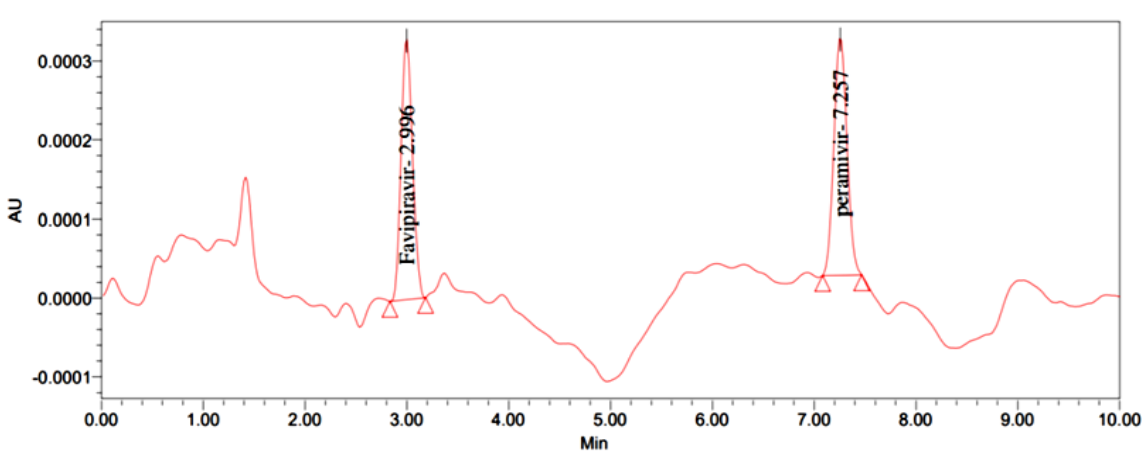

A

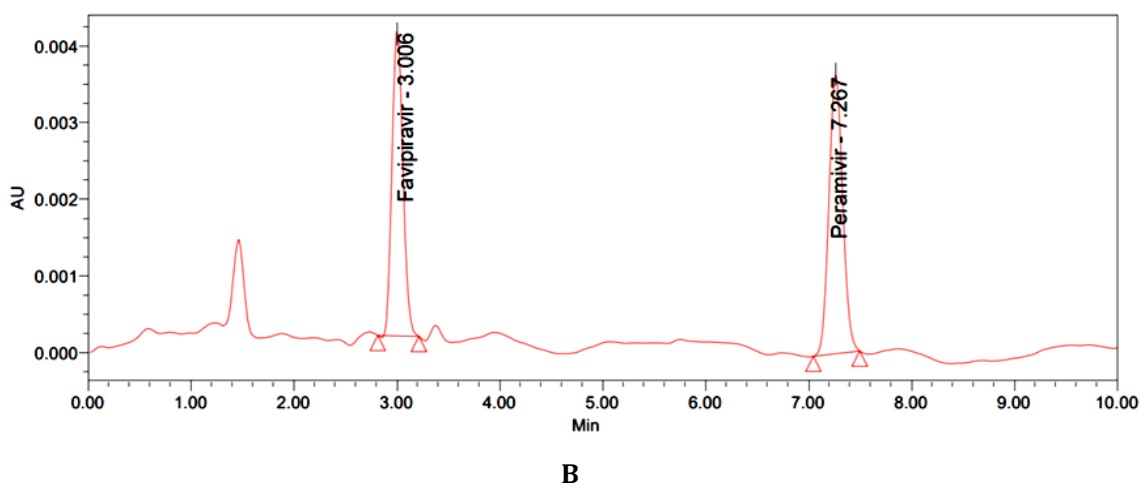

Fig. 6: Chromatogram of (A) LOD and (B) LOQ

Table 7: Robustness data of favipiravir and peramivir

\begin{tabular}{lll}
\hline Parameter name & \% RSD & Peramivir \\
\cline { 2 - 3 } & Favipiravir & 0.70 \\
\hline Flow minus $(0.8 \mathrm{ml} / \mathrm{min}$ & 0.62 & 0.66 \\
Flow plus $(1.2 \mathrm{ml} / \mathrm{min})$ & 0.34 & 0.26 \\
Organic minus $(-10 \%)$ & 0.56 & 0.61 \\
Organic plus $(+10 \%)$ & 0.51 & \\
\hline
\end{tabular}

\section{Stability}

The standard and sample solution was kept at room temperature and at $2-8{ }^{\circ} \mathrm{C}$ up to $24 \mathrm{~h}$. Then these solutions were pumped into the device and calculate the \% of deviation from initial to $24 \mathrm{~h}$
[31]. There was no significant deviation observed and confirmed that the solutions were stable up to $24 \mathrm{~h}$ percentage of the assay was not quite $2 \%$. There is no effect in storage conditions for Favipiravir and Peramivir drugs. The results are given below table 8.

Table 8: Stability results of favipiravir and peramivir

\begin{tabular}{|c|c|c|c|c|}
\hline \multirow[t]{2}{*}{ Stability } & \multicolumn{2}{|c|}{ Favipiravir } & \multicolumn{2}{|c|}{ Peramivir } \\
\hline & Purity & $\%$ of deviation & Purity & $\%$ of deviation \\
\hline Initial & 99.86 & 0.14 & 99.91 & 0.09 \\
\hline $6 \mathrm{H}$ & 99.74 & 0.12 & 99.84 & 0.07 \\
\hline $12 \mathrm{H}$ & 99.62 & 0.24 & 99.73 & 0.18 \\
\hline $18 \mathrm{H}$ & 99.51 & 0.35 & 99.61 & 0.30 \\
\hline $24 \mathrm{H}$ & 99.46 & 0.40 & 99.54 & 0.37 \\
\hline
\end{tabular}

\section{Degradation studies}

The Peramivir and Favipiravir sample was subjected into various forced degradation conditions to effect partial degradation of the drug. Studies of forced degradation have been carried out to find out that the method is suitable for products of degradation. In addition, the studies provide details about the conditions during which the drug is unstable, in order that the measures are often taken during formulation to avoid potential instabilities.

\section{Acid degradation}

In acid degradation was done at $1 \mathrm{~N} \mathrm{HCl}$ and degradation was formed $12.7 \%$ for Favipiravir and $13.5 \%$ for Peramivir.

\section{Alkali degradation}

In alkali degradation was done at $1 \mathrm{~N} \mathrm{NaOH}$ and degradation was formed $13.7 \%$ for Favipiravir and $14.7 \%$ for Peramivir.

\section{Peroxide degradation}

In peroxide degradation was peroformed at $20 \%$ hydrogen peroxide at $15.14 \%$ Favipiravir at $15.14 \%$ and $15.15 \%$ for Peramivir.

\section{Reduction degradation}

In reduction degradation, they formed $13.5 \%$ Favipiravir and Peramivir. 
Table 9: Forced degradation results of favipiravir and peramivir

\begin{tabular}{llll}
\hline Degradation condition & Favipiravir & \multicolumn{2}{c}{ Peramivir } \\
\cline { 2 - 4 } & \% Assay & \% Deg & \% Assay \\
\hline Acid degradation & 87.246 & 12.754 & 86.421 \\
Alkali degradation & 86.271 & 13.729 & 85.284 \\
Peroxide degradation & 84.854 & 15.146 & 84.841 \\
Reduction degradation & 86.412 & 13.588 & 86.472 \\
Thermal degradation & 99.231 & 0.769 & 99.547 \\
Hydrolysis degradation & 99.457 & 0.543 & 99.145 \\
\hline
\end{tabular}

\section{Thermal degradation}

In thermal degradation the sample was degradated $0.76 \%$ for Favipiravir and $0.45 \%$ for Peramivir.

\section{Degradation of hydrolysis}

In hydrolysis degradation the sample was degradated $0.54 \%$ for Favipiravir and $0.85 \%$ for Permaivir.

All degradation results are tabulated in table 9.

\section{CONCLUSION}

We present in this article simple, selective, validated and welldefined stability that shows gradient RP-HPLC methodology for the quantitative determination of Favipiravir and Peramivir. All the products of degradation formed during the stress conditions and the related active pharma ingredients are well separated and peaks were well resolved from each other and separate with an appropriate retention time indicating that the proposed method to be fast, simple, feasible and affordable in RS condition. Therefore the developed method during stability tests, it can be used for routine analysis of production samples and to verify the quality of drug samples during stability studies.

\section{ACKNOWLEDGEMENT}

The authors thankful to management of Sri Satya Sai University of Technology and Medical Sciences for their support to complete this research work.

\section{FUNDING}

Nil

\section{AUTHORS CONTRIBUTIONS}

All the authors have contributed equally.

\section{CONFLICTS OF INTERESTS}

Declared none

\section{REFERENCES}

1. Drug approval package: Rapivab (peramivir) injection U. S. Food and Drug Administration (FDA); 2015.

2. Life-saving H1N1 Drug unavailable to most, CBS Evening News, Atlanta, GA, USA: CBS interactive; 2009.

3. Emergency use authorization granted for Biocryst's Peramivir; 2009.

4. Kohno S, Kida H, Mizuguchi M, Shimada J. Efficacy and safety of intravenous peramivir for treatment of seasonal influenza virus infection. Antimicrob Age Chemother 2010;54:4568-74.

5. Shobugawa Y, Saito R, Sato I, Kawashima T, Dapat C, Dapat IC. Clinical effectiveness of neuraminidase inhibitors-oseltamivir, zanamivir, Laninamivir, and peramivir-for treatment of influenza $\mathrm{A}\left(\mathrm{H}_{3} \mathrm{~N}_{2}\right)$ and $\mathrm{A}\left(\mathrm{H}_{1} \mathrm{~N}_{1}\right)$ pdm09 infection: an observational study in the influenza season in Japan. J Infect Chemother 2012;18:858-64.

6. Tanaka A, Seki M, Kosai K, Kawano S. Peramivir (in Japanese). Japan J Clin Exp Med 2010;87:1702-6.

7. McLaughlin MM, Skoglund EW, Ison MG. Peramivir: an intravenous neuraminidase inhibitor. Expert Opin Pharmacother 2015;16:1889-90.

8. Kohno S, Kida H, Mizuguchi M, Shimada J. Efficacy and safety of intravenous peramivir for treatment of seasonal influenza virus infection. Antimicrob Agents Chemother 2010;54:4568-74.
9. Kohno S, Yen MY, Cheong HJ. Phase III randomized, doubleblind study comparing single-dose intravenous peramivir with oral oseltamivir in patients with seasonal influenza virus infection. Antimicrob Agents Chemother 2011;55:5267-76.

10. Kohno S, Kida $\mathrm{H}$, Mizuguchi $M$. Intravenous peramivir for treatment of influenza $A$ and $B$ virus infection in high-risk patients. Antimicrob Agents Chemother 2011;55:2803-12.

11. drugs.com [Last accessed on 10 Nov 2019]

12. https://www.businessstandard.com/article/companies/glenmark-launches-covid19-drug-fabiflu. [Last accessed on 10 Nov 2019]

13. Du YX, Chen XP. Favipiravir: pharmacokinetics and concerns about clinical trials for 2019-nCov infection. Clin Pharmacol Ther 2020;108:242-7.

14. Shiraki K, Daikoku T. Favipiravir, an anti-influenza drug against life-threatening RNA virus infections. Pharmacol Ther 2020;209:107512.

15. Murugan S, Upendra Janardhan $\mathrm{CH}$, Niranjan Babu M. RP-HPLC method for simultaneous estimation of albendazole and niclosamide in oral suspension for veterinary use. Res J Pharm Tech 2016;9:27-32.

16. Bhavani P, Prasada Rao K, Mohan S. Novel validated reversedphase high-performance liquid chromatography method for determination of glucosamine, diacerein, and methyl sulfonyl methane in micro sample rat plasma and its application to pharmacokinetic and dissolution studies. Asian J Pharm Clin Res 2020;13:50-63.

17. Naresh Kumar DS, Patel D. Stability indicating chromatographic method development and validation for the simultaneous estimation of escitalopram oxalate and flupentixol in its pharmaceutical dosage form by HPLC. WJPR 2017;6:549-66.

18. Supriya T, Naresh D, Vijaya Kumar G, Haneer MA. Stability indicating RP-HPLC method development and validation for simultaneous estimation of escitalopram and flupentixol pure and marketed formulation. Asian J Pharm Res 2018;8:4-10.

19. Shivani CP, Maheshwari DG. Development and validation of UV spectrometric and HPLC method for estimation of escitalopram oxalate and flupentixol dihydrochloride in combined dosage form. AJPTI 2016;4:59-70.

20. Malathi S, Devakumar D. Development and validation of rp-hplc method for the estimation of escitalopram oxalate and flupentixol dihydrochloride in combined dosage form and plasma. Int J Pharm Pharm Sci 2021;13:61-6.

21. Mukta D Naykode, Durgacharan A Bhagwat, Swapnil D Jadhav, Harinath N. Analytical and bio analytical method for quantification of pure azilsartan, not its salt by RP-HPLC. Res J Pharm Tech 2017;10:708-14

22. Mayanka Singh, Manoj Charde, Rajesh Shukla, Rita MC. Determination of calcipotriene in calcipotriene cream $0.05 \%$ w/w by RP-HPLC method development and validation. Res J Pharm Tech 2011;4:1219-23.

23. Malathi S, Arunadevi N. Development and validation of stability-indicating simultaneous estimation of metformin and alogliptin in tablets by high-performance thin layer chromatography. Int J Pharm Pharm Sci 2020;12:68-73.

24. Senthil Rajan D, Muruganathan G, Shivkumar K, Ganesh T. Development and validation of hplc method for simultaneous quantification of vasicine, glycyrrhizin and piperine in poly herbal cough syrup. Int J Curr Pharm Res 2020;12:15-9.

25. Palani Shanmugasundaram, Kamarapu SK. RP-HPLC method for the simultaneous estimation and validation of amlodipine besylate and atenolol in bulk and tablet dosage form in biorelevant dissolution medium (Fassif). Res J Pharm Tech 2017;10:3379-85. 
26. Gomathy S, Narenderan ST, Meyyanathan SN, Gowramma B Development and validation of hplc method for the simultaneous estimation of apigenin and luteolin in commercial formulation. J Crit Rev 2020;7:4785-90.

27. Ashutosh Kumar S, Manidipa Debnath, Seshagiri Rao JVLN, Gowri Sankar D. Development and validation of a sensitive RPHPLC method for simultaneous estimation of rosuvastatin and fenofibrate in tablet dosage form by using PDA detector in gradient mode. Res J Pharm Tech 2016;9:549-54.

28. Malak Y, Al-Bathish AA, Gazy MK, El-Jamal. Rp-hplc and chemometric methods for the determination of two antidiabetic mixtures; metformin hydrochloride-canagliflozin and metformin hydrochloride-gliclazide in their pharmaceutical formulation. Int J Pharm Pharm Sci 2020;12:83-94.
29. Gadhvi MP, Bhandari A, Suhagia BN, Desai UH. Development and validation of RP-HPLC method for simultaneous estimation of atazanavir and ritonavir in their combined tablet dosage form. Res J Pharm Tech 2013;6:200-3.

30. Swati K, Abhishek P, Sushank S, Bothiraja C, Atmaram P. Highperformance liquid chromatography for the simultaneous estimation of cefoperazone and sulbactam in rat plasma and its importance in therapeutic drug monitoring. Int J Pharm Pharm Sci 2020;12:92-7.

31. Vijayakumari M, Balasekhar Reddy Ch. Stability indicating validated hplc method for the determination of zanubrutinib in bulk and pharmaceutical dosage form. Asian J Pharm Clin Res 2020;13:159-62. 